\title{
Feeding practices, physical activity, and fitness in Spanish preschoolers. Influence of sociodemographic outcome measures
}

\author{
Pedro Á. Latorre Román, M.D., ${ }^{a}$ David Mora López, B.S., ${ }^{a}$ and Felipe García Pinillos, B.S. ${ }^{a}$
}

\begin{abstract}
Introduction. Preschool age is critical for the development of adequate eating and physical activity habits.

Objective. The purpose of this study was to analyze the nutritional status, physical activity (PA) and fitness levels in preschool children in relation to gender and parental sociodemographic outcome measures.

Material and methods. Preschool children selected from 30 school facilities in Southern Spain were included.Children's PA and fitness parameters, anthropometry, and nutritional status, and parental sociodemographic outcome measures were recorded.

Results. A total of 1287 children aged between 3 and 6 years old ( 643 boys and 644 girls) participated in the study, together with 1267 parents (72.4\%: mothers, $27.6 \%$ : fathers). Girls had a lower overweight and obesity rate than boys. Significant differences were observed by gender in the consumption of certain food: girls ate more dairy products at breakfast and olive oil, whereas boys ate more fast food and pasta or rice. Boys had a better fitness level. Children from a lower socioeconomic level had a higher body mass index, a worse nutritional status, and a lower PA level. Children whose parents had completed university education had a lower body mass index and a better nutritional status. Conclusions. Preschoolers had a high overweight and obesity rate, and a low PA level, compared to international references. The fitness level of girls was lower than that observed in boys. Children whose parents had a low socioeconomic level and no education had a poor nutritional status. Key words: preschoolers, fitness, physical activity, obesity, nutrition.
\end{abstract}

http:/ /dx.doi.org/10.5546/aap.2016.eng.441

a. Universidad de Jaén, Jaén, Spain.

E-mail address:

Pedro A. Latorre

Román, M.D.,

platorre@ujaen.es

Funding:

None.

Conflict of interest: None.

Received: 02-13-2016 Accepted: 05-20-2016 to occur in nutrition and physical activity (PA) patterns. ${ }^{1}$ In addition, adiposity and low levels of aerobic fitness and PA are associated with a risk for cardiovascular disease in children, and its high prevalence is a major public health problem. ${ }^{2}$

It is necessary to analyze certain modifiable factors (parental influence, social environment, school, leisure time, etc.) and other non-modifiable ones (gender and age) to establish a comprehensive approach to overweight and obesity in preschoolers and its relation to PA. Among modifiable factors, PA stands out because it is inversely associated with overweight. ${ }^{3}$ Several studies have demonstrated that PA level is low in preschool children. ${ }^{4-6}$ Besides, fitness is an important biomarker of health from an early age. ${ }^{7}$ Overweight and adiposity have a negative influence on children's level of fitness, ${ }^{8}$ and a significant connection has been observed between growth and fitness. ${ }^{9,10}$ In addition to PA, diet is also one of the most important exogenous factors for child growth.

Preschool age is an ideal period to develop adequate eating and PA habits; it is a critical time for obesity prevention, which is associated with negative consequences on health that may persist through adolescence and adulthood..$^{8,11,12}$ Therefore, assessing the nutritional status and PA level of preschoolers should be an essential element for health monitoring and follow-up in this population.

Considering the preceding information, the proposed hypothesis is that, at preschool age, eating and PA habits may be affected by gender and certain parental sociodemographic characteristics. The purpose of 
this study was to assess the nutritional status, weight status, PA and fitness levels of preschool children in relation to gender and other parental sociodemographic outcome measures.

\section{POPULATION AND METHODS}

Preschool children were randomly selected from 30 school facilities in Southern Spain and included in the study. Inclusion criteria were being in the Preschool Education system and not having a physical and/or intellectual disability. Parents signed an informed consent form for voluntary participation in this study (essential for children inclusion). The study was done in accordance with the principles of the Declaration of Helsinki (2013 version). The study was approved by the Ethics Committee of Universidad de Jaén.

A specially designed sociodemographic questionnaire was used to collect information about parents, including their level of education, marital status, and socioeconomic level (based on their self-perception). Anthropometric parameters included height $(\mathrm{cm})$, measured with a stadiometer (Seca 222, Hamburg, Germany); weight (kg), measured with a scale (Seca 634, Hamburg, Germany); and body mass index (BMI), which was recorded using the $B M I=$ weight $(\mathrm{kg}) /$ height $(\mathrm{m})^{2}$ equation. Waist circumference was also measured at the level of the umbilicus using a Seca 201 ergonomic circumference measuring tape. Fitness was analyzed using the test battery proposed by Latorre et al. (2015), ${ }^{13}$ which includes basic components of physical and motor status, such as strength, endurance, speed, and balance. A manual dynamometry was also included to assess handgrip strength. Nutritional status, screen time (activities done in front of a screen, such as watching TV, using a tablet, playing video games, or using a mobile phone or a computer, etc.), and PA were analyzed using the Krece Plus questionnaire, which is made up of 16 questions related to diet and 2 questions on screen time and PA outside school. ${ }^{14}$ Parental sit-down time was recorded using item 7 from the International Physical Activity Questionnaire - Short Form (IPAQ-SF). ${ }^{15}$

Every test was conducted in the school, either the sports facilities or classrooms, by expert researchers and in the presence of each student group's teachers. Parents completed the selfadministered questionnaires at home. Then children were assessed in two separate sessions with a 48-hour interval during their school day
(9 am to $2 \mathrm{pm}$ ), for approximately 40 minutes each time. On the first day, the following tests were done: handgrip strength (two attempts with each hand), balance (two attempts with each leg), and long jump (two attempts). On the second day, the $20 \mathrm{~m}$ sprint (two attempts) and the $10 \times 20 \mathrm{~m}$ sprint (one attempt) were completed. Prior to physical tests, children did warm-up exercises based on continuous running and joint mobilization; besides, the research team demonstrated the tests, and children completed familiarization activities. The best attempts achieved in each test were selected, except for the manual dynamometry and the balance test, for which the average result of both hands and legs, respectively, was selected as the best attempt. All children were motivated to give their maximum physical performance through oral instructions encouraging them to run faster, jump further, etc.

The sample size for an infinite population with an unknown prevalence, where $p=q=0.50$, with a $99 \%$ confidence level and a $5 \%$ error, was 645 subjects. Data provided by the Regional Government of Andalusia on Andalusian Preschool Education were used for sample selection.

Data were analyzed using the SPSS statistical software, v.19.0 for Windows (SPSS Inc., Chicago, USA). The significance level was established at $p<0.05$, with a $95 \%$ confidence level. Data were described as mean descriptive statistics, standard deviation, and percentage. The normal distribution of data and homogeneity of variances were verified using the KolmogorovSmirnov test and the Levene's test, respectively. Differences among gender, level of education, and socioeconomic level were analyzed using an analysis of variance (ANOVA) and a post hoc test with Bonferroni's correction. Weight status and the Krece Plus questionnaire were analyzed by item in relation to gender using the $\chi^{2}$ test. Lastly, Pearson's correlation among the different outcome measures was also implemented.

\section{RESULTS}

The study was conducted between April and May of 2015. A total of 1287 children aged 3 to 6 years old participated (age $=50.90$ months, $\left.\mathrm{BMI}=16.03 \pm 2.13 \mathrm{~kg} / \mathrm{m}^{2}\right), 643$ boys and 644 girls, and 1267 parents (72.4\%: mothers, $27.6 \%$ : fathers).

Figure 1 shows the flow chart of participants. Table 1 describes the sociodemographic outcome measures corresponding to one of the parents.

Differences were significant in terms of 
weight status by gender $(p=0.004)$ : girls had lower overweight and obesity levels, $7.0 \%-9.2 \%$ versus $9.7 \%-13.9 \%$, respectively; and the overall overweight and obesity prevalence was $8.3 \%$ and $11.5 \%$, respectively.

Table 2 shows the results of the Krece Plus questionnaire in terms of percentage of response to each item. Significant differences by gender were observed in the consumption of certain food: girls ate more dairy products at breakfast and olive oil, whereas boys ate more fast food and pasta or rice.

TABLE 1. Parental sociodemographic characteristics

\begin{tabular}{lc}
\hline Marital status & $\mathbf{n}(\mathbf{\%})$ \\
\hline Single & $53(4.2)$ \\
Married or living with a couple & $826(65.2)$ \\
Divorced/separated & $372(29.4)$ \\
Widowed & $16(1.2)$ \\
Total & $1267(100)$ \\
Socioeconomic level & \\
Low & $107(8.6)$ \\
Middle & $814(65.6)$ \\
High & $319(25.8)$ \\
Total & $1240(100)$ \\
Education level & \\
No education & $32(2.5)$ \\
Primary education & $316(25)$ \\
Secondary education & $483(38.2)$ \\
University education & $433(34.3)$ \\
Total & $1264(100)$ \\
Daily sit-down time in minutes & \\
Mean (SD) & $248.20(168.31)$ \\
\hline
\end{tabular}

SD: standard deviation.
Table 3 describes the different outcome measures by gender. Significant differences were observed in BMI, which was higher in boys. In turn, boys had better results in the long jump, speed, endurance, and handgrip strength tests.

Table 4 indicates the results of the different outcome measures by parental socioeconomic level. Children from a lower socioeconomic level had a higher BMI, a worse nutritional status, and a lower PA level. Screen time was shorter in those who had a higher socioeconomic level but their performance in physical tests, e.g. long jump and speed, was worse.

Table 5 describes the different outcome measures by parental level of education. Children whose parents had completed university education had a lower BMI, a better nutritional status, and a better result in the long jump test.

\section{Figure 1. Flow chart of participants}

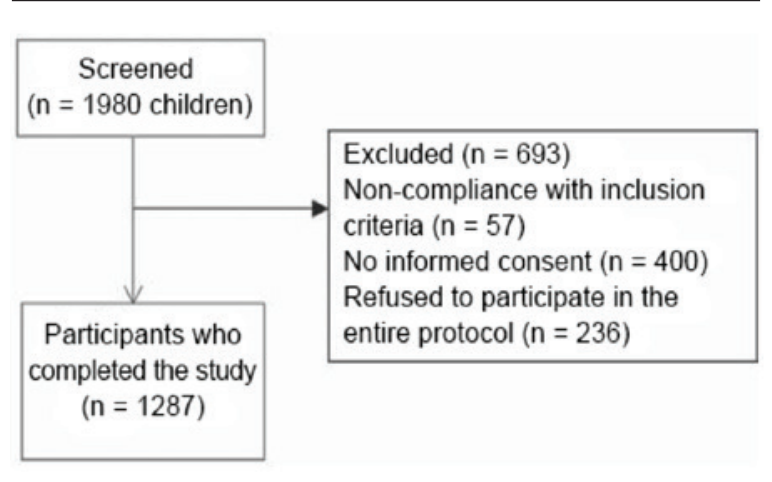

TABLE 2. Results from the Krece Plus questionnaire as per parents' percentage of response to each item in the overall sample and by gender

\begin{tabular}{|c|c|c|c|c|c|}
\hline Items & $\begin{array}{c}\mathrm{N} \\
\text { parents }\end{array}$ & $\begin{array}{c}\text { Total } \\
\text { percentage }\end{array}$ & $\begin{array}{c}\text { Girls } \\
(\%)\end{array}$ & $\begin{array}{c}\text { Boys } \\
(\%)\end{array}$ & $p$-value \\
\hline Skips breakfast & 1248 & 1.5 & 1.5 & 1.6 & 0.817 \\
\hline Has dairy products (milk or other) for breakfast & 1257 & 93.3 & 94.9 & 91.7 & 0.024 \\
\hline Has cereals or cereal products for breakfast & 1254 & 68 & 66.6 & 69.4 & 0.290 \\
\hline Has cake or pastries for breakfast & 1243 & 27.8 & 26.9 & 28.8 & 0.442 \\
\hline Eats a fruit or drinks fruit juice every day & 1263 & 79.2 & 78.4 & 79.9 & 0.516 \\
\hline Eats a second serving of fruit every day & 1257 & 38.9 & 37.7 & 40.2 & 0.360 \\
\hline Has a second serving of dairy products throughout the day & 1257 & 85.7 & 85.6 & 85.9 & 0.862 \\
\hline Regularly eats fresh or cooked vegetables once a day & 1265 & 62.9 & 63.9 & 61.8 & 0.439 \\
\hline Eats fresh or cooked vegetables more than once a day & 1262 & 23 & 21.8 & 24.2 & 0.315 \\
\hline Regularly eats fish (more than twice or thrice a week) & 1264 & 76.9 & 77.5 & 76.3 & 0.617 \\
\hline Eats burgers, hot dogs or pizza once or more times a week & 1266 & 29.7 & 25 & 34.3 & $<0.001$ \\
\hline Likes legumes (eats lentils, beans; more than once a week) & 1267 & 84.1 & 84.7 & 83.5 & 0.572 \\
\hline Eats candies and sweet snacks several times a day & 1266 & 22.9 & 23 & 22.8 & 0.930 \\
\hline Eats pasta or rice almost daily (more than 5 times a week) & 1267 & 31.6 & 28.3 & 34.9 & 0.012 \\
\hline Uses olive oil at home & 1267 & 95.6 & 97.1 & 94.1 & 0.008 \\
\hline Drinks alcohol ( $\geq 1$ /week) & 1266 & 0 & 0 & 0 & -- \\
\hline
\end{tabular}


Pearson's correlation did not reveal a significant association between parental daily sit-down time and studied outcome measures.

\section{DISCUSSION}

The most relevant finding of this study is that, in the studied population, child gender and socioeconomic level, and parental level of education had an effect on different aspects of the weight status, the nutritional status, and PA and fitness levels of preschoolers.

In terms of gender, girls had a lower overweight and obesity prevalence than boys, whereas boys had a better fitness level, with no differences observed in nutritional status, PA level, and screen time. In addition, no association was found between BMI and PA level, screen time, nutritional status, and the rest of fitness tests, except for handgrip strength.

In relation to nutritional status, and considering the scale proposed by Serra et al., ${ }^{14}$ preschool children included in this study had a mean nutritional status, which required diet improvements and a visit to their pediatrician six months later. However, children whose parents had a low socioeconomic level and no education had a very low nutritional status, which required urgent diet modifications and a visit to their pediatrician.

In terms of PA level, preschool children

TABLE 3. Age, anthropometric outcome measures, nutritional status, physical activity level, screen time, and fitness level by gender

\begin{tabular}{lccc}
\hline & $\begin{array}{c}\text { Boy } \\
\text { Mean (SD) } \\
\mathbf{n = 6 4 3}\end{array}$ & $\begin{array}{c}\text { Girl } \\
\text { Mean (SD) } \\
\mathbf{n = 6 4 4}\end{array}$ & $p$-value \\
\hline Age (months) & $51.13(10.41)$ & $50.68(10.86)$ & 0.493 \\
BMI (kg/m ${ }^{2}$ & $16.19(2.17)$ & $15.87(2.08)$ & 0.007 \\
Hip circumference (cm) & $55.01(5.71)$ & $55.46(5.92)$ & 0.228 \\
Total Krece Plus score (0-10) & $6.52(2.06)$ & $6.56(2.00)$ & 0.716 \\
Weekly physical activity level (hours) & $1.87(1.63)$ & $1.71(1.55)$ & 0.079 \\
Daily screen time (hours) & $3.14(6.64)$ & $3.13(6.63)$ & 0.971 \\
Long jump (cm) & $73.28(25.83)$ & $65.98(25.55)$ & $<0.001$ \\
20 m sprint (s) & $6.16(1.21)$ & $6.55(1.26)$ & $<0.001$ \\
Endurance (s) & $83.04(19.54)$ & $85.75(19.65)$ & 0.016 \\
Balance (s) & $8.85(9.67)$ & $9.30(10.43)$ & 0.435 \\
Handgrip strength $(\mathrm{kg})$ & $5.80(2.03)$ & $5.33(1.99)$ & $<0.001$ \\
\hline
\end{tabular}

SD: standard deviation. BMI: body mass index.

TABLE 4. Age, anthropometric outcome measures, nutritional status, physical activity level, screen time, and fitness level by parental socioeconomic level

\begin{tabular}{|c|c|c|c|c|c|}
\hline & $\begin{array}{c}\text { Low } \\
\text { Mean (SD) } \\
\mathrm{n}=102\end{array}$ & $\begin{array}{c}\text { Middle } \\
\text { Mean (SD) }^{\mathrm{b}} \\
\mathrm{n}=768\end{array}$ & $\begin{array}{c}\text { High } \\
\text { Mean (SD) } \\
n=293\end{array}$ & $P$-value & $\begin{array}{c}\text { Post hoc } \\
\text { test }\end{array}$ \\
\hline Age (months) & $50.37(10.32)$ & $51.21(10.65)$ & $52.13(10.85)$ & 0.709 & \\
\hline BMI $\left(\mathrm{kg} / \mathrm{m}^{2}\right)$ & $16.53(2.53)$ & $15.94(1.99)$ & $16.02(2.36)$ & 0.038 & $a>b^{*}$ \\
\hline Hip circumference $(\mathrm{cm})$ & $54.88(6.86)$ & $54.94(5.62)$ & $53.27(5.81)$ & 0.563 & \\
\hline Total Krece Plus score $(0-10)$ & $5.91(2.39)$ & $6.53(1.98)$ & $7.21(1.77)$ & $<0.001$ & $\mathrm{a}<\mathrm{b}^{*}, \mathrm{a}<\mathrm{c}^{* * *}, \mathrm{~b}<\mathrm{c}^{* * *}$ \\
\hline Weekly physical activity level (hours) & $1.42(1.54)$ & $1.83(1.60)$ & $2.02(1.63)$ & 0.006 & $\mathrm{a}<\mathrm{c}^{* *}$ \\
\hline Daily screen time (hours) & $3.29(6.15)$ & $3.70(8.01)$ & $1.85(0.93)$ & $<0.001$ & $\mathrm{~b}>\mathrm{c}^{* * *}$ \\
\hline Long jump (cm) & $70.32(28.29)$ & $72.13(26.44)$ & $61.50(22.50)$ & $<0.001$ & $a>c^{*}, b>c^{* * *}$ \\
\hline $20 \mathrm{~m}$ sprint (s) & $6.30(1.17)$ & $6.26(1.21)$ & $6.66(1.32)$ & $<0.001$ & $\mathrm{~b}<\mathrm{c}^{* * *}$ \\
\hline Endurance (s) & $87.02(24.05)$ & $84.15(19.86)$ & $81.99(16.41)$ & 0.092 & \\
\hline Balance (s) & $10.16(11.84)$ & $9.00(9.61)$ & 9.59 (11.03) & 0.475 & \\
\hline Handgrip strength $(\mathrm{kg})$ & $5.69(1.74)$ & $5.57(2.08)$ & $6.33(2.24)$ & 0.359 & \\
\hline
\end{tabular}

SD: standard deviation. BMI: body mass index. ${ }^{*} \mathrm{p}<0.05,{ }^{* *} \mathrm{p}<0.01,{ }^{* * *} \mathrm{p}<0.001$. 
assessed in this study evidenced a very low weekly PA level as per international recommendations. ${ }^{16}$ In addition, daily screen time was longer than weekly time devoted to PA; this together with a high overweight and obesity prevalence as per reference data by De Onis et al. ${ }^{17}$ indicated that this population is highly sensitive to health problems related to overweight and a sedentary lifestyle. In this regard, Van Stralen et al. ${ }^{18}$ highlighted a positive association among a sedentary lifestyle -mainly screen time- and BMI and waist circumference. Hinkley et al. ${ }^{19}$ indicated that most young children did not take part in adequate PA but spent excessive time in front of a screen. In relation to gender, and consistent with this study, other authors found no differences between preschool boys and girls in terms of PA level, regardless of whether the assessment was completed objectively (accelerometry) or through parental reports. ${ }^{20}$ In addition, overweight children were significantly less active, though no important differences were observed among girls. ${ }^{21}$

Considering the influence of parental sociodemographic characteristics on the different outcome measures, children whose parents had a high sociodemographic level had a better nutritional status, and spent more time doing PA and less time using the screen. Children whose parents had completed university education had a lower BMI, a better nutritional status, and a better result in the long jump test. In this sense, Sotos et al. ${ }^{22}$ underlined that both education level and socioeconomic status affected nutritional status during childhood.

Also, in this study, a parental sedentary lifestyle was not associated with any of the analyzed outcome measures. However, Hinkley et al. ${ }^{23}$ pointed out that children whose parents had an active lifestyle tended to be more active. Likewise, Hesketh et al. ${ }^{24}$ indicated that maternal daily PA levels were associated with every PA intensity levels in preschoolers.

Therefore, PA is one of the factors that has an impact on the healthy development of children, but most preschoolers tend to have a sedentary lifestyle. ${ }^{25} \mathrm{O}^{\prime}$ Dwyer et al. ${ }^{26}$ suggested that school accounted for an environment that promoted a sedentary lifestyle. In Spain, the situation is the same as pointed out by other authors ${ }^{27}$ in relation to PA at school; thus, although schools may offer a unique opportunity for structured PA, there is a tendency to cut off physical education classes in pursuit of improving academic outcomes. Summerbell et al. ${ }^{28}$ recommended a series of guidelines to conduct interventions in the setting of preschool PA, such as boosting active transportation for short distances, discouraging the installation of screens in the bedroom, promoting non-competitive PA, improving all playground areas, providing comfortable clothes, offering games during school breaks, encouraging children to be active, and reducing overall classroom sedentary time.

A limitation of this study is its cross-sectional nature, so we must be careful regarding results

TABle 5. Age, anthropometric outcome measures, nutritional status, physical activity level, screen time, and fitness level by parental level of education

\begin{tabular}{|c|c|c|c|c|c|c|}
\hline & $\begin{array}{l}\text { No education } \\
\text { Mean }(S D)^{a} \\
n=26\end{array}$ & $\begin{array}{l}\text { Primary education } \\
\text { Mean (SD) } \\
n=289\end{array}$ & $\begin{array}{l}\text { Secondary education } \\
\text { Mean (SD) } \\
n=446\end{array}$ & $\begin{array}{l}\text { University education } \\
\text { Mean (SD) } \\
\text { n= } \\
\text { d14 }\end{array}$ & $p$-value & $\begin{array}{c}\text { Post hoc } \\
\text { Test }\end{array}$ \\
\hline Age (months) & $48.00(8.72)$ & $51.47(10.65)$ & $51.54(11.07)$ & $50.53(10.29)$ & 0.327 & \\
\hline $\mathrm{BMI}\left(\mathrm{kg} / \mathrm{m}^{2}\right)$ & $16.88(3.21)$ & $16.28(2.28)$ & $15.95(2.17)$ & $15.86(1.90)$ & 0.017 & \\
\hline Hip circumference $(\mathrm{cm})$ & $54.30(5.79)$ & $54.67(5.48)$ & $54.84(6.34)$ & $55.07(5.22)$ & 0.879 & \\
\hline Total Krece Plus score (0-10) & $5.92(2.93)$ & $6.55(1.99)$ & $6.66(1.98)$ & $6.85(1.89)$ & 0.042 & \\
\hline $\begin{array}{l}\text { Weekly physical activity } \\
\text { level (hours) }\end{array}$ & $1.75(1.64)$ & $1.74(1.61)$ & $1.77(1.54)$ & $1.98(1.66)$ & 0.163 & \\
\hline Daily screen time (hours) & $2.75(1.43)$ & $2.98(6.15)$ & $3.11(6.87)$ & $3.27(7.09)$ & 0.939 & \\
\hline Long jump $(\mathrm{cm})$ & $64.41(29.41)$ & $65.28(25.60)$ & $69.75(25.37)$ & $71.97(26.68)$ & 0.009 & $\mathrm{~b}<\mathrm{d}^{* *}$ \\
\hline 20 m sprint (s) & $5.98(1.11)$ & $6.35(1.30)$ & $6.36(1.25)$ & $6.37(1.20)$ & 0.495 & \\
\hline Endurance (s) & $90.88(23.96)$ & $83.04(18.20)$ & $83.69(19.75)$ & 84.19 (19.73) & 0.281 & \\
\hline Balance (s) & $11.69(10.49)$ & $10.07(11.36)$ & $9.36(10.30)$ & $8.72(9.68)$ & 0.255 & \\
\hline Handgrip strength (kg) & $5.90(1.55)$ & $5.44(2.07)$ & $5.62(1.93)$ & $5.59(2.13)$ & 0.707 & \\
\hline
\end{tabular}

SD: standard deviation. BMI: body mass index.** $\mathrm{p}<0.01$ 
and refrain from making causal inferences. Another limitation is that other factors that may have influenced on studied outcome measures were not considered, such as social and physical setting, e.g. sports facilities, urban planning, transportation systems, parks and trails, etc.

Nevertheless, a strength of this research is that the sample was ample enough, and that recorded outcome measures had scarcely been approached in other similar studies, such as fitness.

In practical terms, interventions aimed at improving PA in preschoolers, both in and outside the school, are essential, especially if accompanied by nutritional education provided to parents with less financial resources and a poor level of education.

\section{CONCLUSIONS}

To sum up, preschoolers included in this study had a high overweight and obesity rate, and a low PA level, compared to international references. The fitness level of girls was lower than that observed in boys. Lastly, children whose parents had a low socioeconomic level and no education had a poor nutritional status.

\section{REFERENCES}

1. De Onis M, Onyango AW, Borghi E, Siyam A, et al. Development of a WHO growth reference for schoolaged children and adolescents. Bull World Health Organ 2007;85(9):660-7.

2. Bürgi F, Meyer U, Granacher U, Schindler C, et al. Relationship of physical activity with motor skills, aerobic fitness and body fat in preschool children: a cross-sectional and longitudinal study (Ballabeina). Int J Obes (Lond) 2011;35(7):937-44.

3. Te Velde SJ, Van Nassau F, Uijtdewilligen L, Van Stralen MM, et al. Energy balance-related behaviours associated with overweight and obesity in preschool children: a systematic review of prospective studies. Obes Rev 2012;13 Suppl 1(2):56-74.

4. De Bock F, Genser B, Raat H, Fischer JE, et al. A participatory physical activity intervention in preschools: a cluster randomized controlled trial. Am J Prev Med 2013;45(1):64-74.

5. Grzywacz JG, Suerken CK, Zapata Roblyer MI, Trejo G, et al. Physical activity of preschool-aged Latino children in farmworker families. Am J Health Behav 2014;38(5):717-25.

6. Tucker P. The physical activity levels of preschoolaged children: a systematic review. Early Child Res $Q$ 2008;23(4):547-58.

7. Ortega FB, RuizJR, Castillo MJ,Sjöström M. Physical fitness in childhood and adolescence: a powerful marker of health. Int J Obes (Lond) 2008;32(1):1-11.

8. Kondric M, Trajkovski B, Strbad M, Foretic N, et al. Anthropometric influence on physical fitness among preschool children: gender-specific linear and curvilinear regression models. Coll Antropol 2013;37(4):1245-52.

9. Ortega FB, Artero EG, Ruiz JR, España-Romero V, et al. Physical fitness levels among European adolescents: the HELENA study. Br J Sports Med 2011;45(1):20-9.
10. Travill AL. Correlation between growth and physical fitness of socially disadvantaged girls. South African Journal for Research in Sport, Physical Education and Recreation 2011;33(3):9069.

11. Reilly JJ. Descriptive epidemiology and health consequences of childhood obesity. Best Pract Res Clin Endocrinol Metab 2005;19(3):327-41.

12. Singh AS, Mulder C, Twisk JW, Van Mechelen W, et al. Tracking of childhood overweight into adulthood: a systematic review of the literature. Obes Rev 2008;9(5): 474-88.

13. Latorre Román PA, Mora López D, Fernández Sánchez M, Salas Sánchez J, et al. Test-retest reliability of a field-based physical fitness assessment for children aged 3-6 years. Nutr Hosp 2015;32(4):1683-8.

14. Serra Majem L, Aranceta Bartrina J, Ribas Barba L, Sangil Monroy $\mathrm{M}$, et al. Crecimiento y desarrollo: dimensión alimentaria y nutricional. El cribado del riesgo nutricional en pediatría. Validación del test rápido Krece Plus y resultadosen la población española. In: Serra Majem L, Aranceta Bartrina J, Rodríguez Santos F, eds. Crecimiento y desarrollo. Estudio enKid. Barcelona: Masson; 2003. Pages45-51.

15. Craig CL, Marshall AL, Sjöström M, Bauman AE, et al. International physical activity questionnaire: 12-country reliability and validity. Med Sci Sports Exerc 2003;35(8): 1381-95.

16. Organización Mundial de la Salud. Recomendaciones mundiales sobre actividad física para la salud. Ginebra: Organización Mundial de la Salud; 2010.

17. De Onis M, Blössner M, Borghi E. Global prevalence and trends of overweight and obesity among preschool children. Am J Clin Nutr 2010;92(5):1257-64.

18. Van Stralen MM, Te Velde SJ, Van Nassau F, Brug J, et al. Weight status of European preschool children and associations with family demographics and energy balancerelated behaviours: a pooled analysis of six European studies. Obes Rev 2012;13(Suppl 1):29-41.

19. Hinkley T, Salmon J, Okely AD, Crawford D, et al. Preschoolers' physical activity, screen time, and compliance with recommendations. Med Sci Sports Exerc 2012;44(3): 458-65.

20. Taylor RW, Murdoch L, Carter P, Gerrard DF, et al. Longitudinal study of physical activity and inactivity in preschoolers: the FLAME study. Med Sci Sports Exerc 2009;41(1):96-102.

21. Trost SG, Sirard JR, Dowda M, Pfeiffer KA, et al. Physical activity in overweight and nonoverweight preschool children. Int J Obes Relat Metab Disord 2003;27(7):834-9.

22. Sotos-Prieto M, Santos-Beneit G, Pocock S, Redondo J, et al. Parental and self-reported dietary and physical activity habits in pre-school children and their socio-economic determinants. Public Health Nutr 2015;18(2):275-85.

23. Hinkley T, Crawford D, Salmon J, Okely AD, etal. Preschool children and physical activity. A review of correlates. Am J Prev Med 2008;34(5):435-41.

24. Hesketh KR, Goodfellow L, Ekelund U, McMinn AM, et al. Activity levels in mothers and their preschool children. Pediatrics 2014;133(4):e973-80.

25. Dolinsky DH, Brouwer RJN, Evenson KR, Siega-Riz AM, et al. Correlates of sedentary time and physical activity among preschool-aged children. Prev Chronic Dis 2011;8(6):A131.

26. O'Dwyer M, Fairclough SJ, Ridgers ND, Knowles ZR, et al. Patterns of objectively measured moderate-to-vigorous physical activity in preschool children. J Phys Act Health 2014;11(6):1233-8. 
27. Singh A, Uijtdewilligen L, Twisk JW, van Mechelen W, et al. Physical activity and performance at school: a systematic review of the literature including a methodological quality assessment. Arch Pediatr Adolesc Med 2012;166(1):49-55.
28. Summerbell CD, Moore HJ, Vögele C, Kreichauf S, et al. Evidence-based recommendations for the development of obesity prevention programs targeted at preschool children. Obes Rev 2012;13(Suppl 1):129-32. 